\title{
Fluoxetine Disrupts the Integration of Anxiety and Aversive Memories
}

\author{
Aldemar Degroot' and George G Nomikos*, \\ 'Eli Lilly and Company, Lilly Corporate Center, Neuroscience Discovery Research, Indianapolis, IN, USA
}

\begin{abstract}
Anxiety disorders may result from an overexpression of aversive memories. Evidence suggests that the hippocampal cholinergic system could be the point of convergence of anxiety and memory. We propose that clinically effective anxiolytics may exert their effect by interfering with this integration mechanism. To assess anxiety and aversive memory, we used the shock-probe burying test. A reduction in anxiety in this test is indicated by decreased burying, whereas impaired cognition is reflected by an increased number of probe-contacts and/or reduced retention latency. Both an aversive stimulus and the memory of that stimulus significantly increased hippocampal acetylcholine (ACh) levels (Experiment I). In fact, the memory of the event seemed to be more important than the event itself since the aversive memory induced a greater increase in hippocampal ACh. Injections (i.p.) of fluoxetine (Prozac ${ }^{\mathbb{R}}$ ) reduced burying behavior, while not affecting probe contacts or retention latency (Experiment 2). Although injections of fluoxetine did not affect basal hippocampal ACh efflux (Experiment 3), fluoxetine abolished the increase in ACh induced by the aversive stimulus and the memory of that stimulus (Experiment 4), emphasizing the significance of aversive memories in anxiety disorders. These actions may be mediated by a decrease in the event-related enhancement in cholinergic neurotransmission through MI cholinergic receptors (Experiment 5). Therefore, anxiety disorders may stem from an unopposed formation of aversive memories and clinically effective anxiolytics hinder the association between emotional and cognitive processing. This reduces the emotional impact of aversive memories, thereby opposing consequent anxiety.

Neuropsychopharmacology (2005) 30, 39|-400, advance online publication, 8 December 2004; doi: | 0.1 038/sj.npp. I 300624
\end{abstract}

Keywords: cholinergic receptor; fluoxetine; SSRl; anxiety; experimental animal models; rats

\section{INTRODUCTION}

Preclinical and clinical studies suggest that there exists a neurobiological link between emotional and cognitive processes (Bell and Wolfe, 2004; Clark and McManus, 2002; Ishigooka, 2003; Skelton et al, 2003). Accordingly, anxiety disorders may result from an overexpression of aversive memories (Crestani et al, 1999; Pare, 1996). Clinically effective anxiolytics, then, may reduce anxiety through a disruption of the association between emotion and cognition. Evidence in support of this theory comes from both animal and human research. For example, rats injected with benzodiazepines or SSRIs, such as fluoxetine, show diminished aversive memory formation (Cole, 1986; Monleon et al, 2002; Pain et al, 2002) that may contribute to their well-documented anxiolytic effects in animal models

\footnotetext{
*Correspondence: Dr GG Nomikos, Eli Lilly and Company, Lilly Corporate Center, Indianapolis, IN 46285-0510, USA, Tel: + I 317 433 254I, Fax: + I 317276 5546, E-mail: gnomikos@lilly.com Received 24 August 2004; revised 13 October 2004; accepted 19 October 2004

Online publication: 22 October 2004 at http://www.acnp.org/citations/ NPPI02204040385//default.pdf
}

and in the clinic (Atack, 2003; Bourin and Hascoet, 2001; Hashimoto et al, 1996; Sanchez and Meier, 1997).

Indirect evidence implicates the hippocampus as the site where anxiety and memory converge. It has been found that ablation of the hippocampus reduces rats' fear reactions and decreases cognitive performance. For instance, both electrolytic and excitoxic lesions of the hippocampus induce anxiolysis and impair learning and memory (Degroot and Treit, 2004; Fanselow, 2000; Treit and Menard, 1997). More specifically, neurochemical data indicate that the hippocampal cholinergic system may be involved in the integration of anxiety and memory. Thus, fluctuations of ACh efflux in the hippocampus are associated with modulations of emotionality and cognition (Egawa et al, 2002; Olariu et al, 2001; Decker et al, 1994; Degroot and Treit, 2002; Kawasaki et al, 1996). Interestingly, benzodiazepines, which decrease anxiety and interfere with aversive memory formation, also decrease hippocampal ACh efflux. Based on these data we hypothesized that the hippocampal cholinergic system integrates emotional and cognitive responses and that anxiolytics exert their effect through an interaction with this neurotransmitter system.

To test our hypothesis, we determined the effect of anxiety and aversive memories on hippocampal ACh efflux 
using in vivo microdialysis in the rat. Then, we set forth to determine if fluoxetine mediates its anxiolytic effects through changes in hippocampal cholinergic neurotransmission. We used the shock-probe burying test to assess emotional and cognitive responses to an aversive stimulus since the hippocampal cholinergic system has been previously implicated in this model (Degroot and Treit, 2002, 2003; Degroot et al, 2001). In the shock-probe test, rats are exposed to an electrified probe during a training session. Following contact with the probe, they commence to bury the probe as a defensive mechanism (active avoidance). After 7 days, the rats are returned to the shock-probe chamber for a retention session. Increased burying reflects increased anxiety levels, whereas increased probe-contacts or decreased retention latency implicates impaired short- and long-term memory, respectively. The interval between the training and the retention sessions was based on other studies where the retention session of the shock-probe was used to measure aversive memory performance (Lehmann et al, 2000; Shah and Treit, 2003).

\section{MATERIALS AND METHODS}

\section{Subjects}

Animals were naïve, male albino Sprague-Dawley rats, purchased from Charles River (USA), weighing 250-300 g at the time of testing. Each rat was individually housed in a polycarbonate cage and maintained on a $12: 12 \mathrm{~h}$ light/dark cycle (lights on at 0700), with food and water available ad libitum. Behavioral testing occurred between 0900 and 1700. All studies were carried out in accordance with the guidelines set forth by the National Institutes of Health and implemented by the Animal Care and Use Committee of Eli Lilly and Company.

\section{Shock-Probe Burying Test}

The behavioral procedures were the same as those used in previous experiments (Degroot and Treit, 2002; Treit et al, 1994). All behavioral responses were scored live by an observer and recorded on videotape for ensuing analysis. All testing occurred at least 7 days postsurgery.

Both anxiety and cognition were assessed in the shockprobe burying test. In this test, rats shocked from a stationary, electrified probe push bedding material from the floor of the experimental chamber toward the shock-probe (ie they bury the probe), avoid further contacts with the probe, and exhibit freezing behavior (Treit et al, 1994, 1981; Frye and Seliga, 2003; Pinel and Treit, 1978). In rats it has been demonstrated that anxiolytic drugs such as diazepam decrease burying towards the shock-probe (de Boer et al, 1990; Treit et al, 1993; Tsuda et al, 1988), whereas anxiogenic drugs such as yohimbine increase shock-probe burying (Tsuda et al, 1988). During the training session, burying behavior and the total number of contact-induced shocks each rat received were measured. The rat's reactivity to each shock was scored according to the following scale (Pesold and Treit, 1992): (1) flinch involving only head or forepaw, (2) whole-body flinch, with or without slow ambulation away from the probe, (3) whole-body flinch, and/or jumping, followed by immediate ambulation away from the probe, and (4) whole-body flinch and jump (all four paws in the air), followed by immediate and rapid ambulation to the opposite end of the chamber. The time the rat spent immobile was used as an index of locomotor activity. During the retention session the amount of time it took for the rats to contact the probe was used as a measure of retention latency.

\section{Statistics}

Dialysis data are expressed as multifold change from baseline. The dialysis data were analyzed with two-way, that is, treatment $\times$ time ANOVA followed by Bonferroni tests. Subsequently, individual time points were analyzed with $t$-tests if there were only two groups or a one-way ANOVA followed by LSD post hoc tests if more than two groups were analyzed. Similarly, the behavioral data were analyzed using $t$-tests (two groups) or ANOVAs followed by LSD tests (more than two groups). In order to correct for heterogeneity of variance, the burying scores were transformed to their square roots (SQRT) prior to analysis.

Experiment 1A: training. At least 7 days prior to the experiment, rats were anesthetized and implanted with microdialysis probes aimed at the hippocampus as described (Tzavara et al, 2003). At 3 days after surgery, rats were acclimated to the shock-probe burying apparatus over 4 consecutive days (45-min sessions). On the testing day, rats were placed in a microdialysis bowl. Animals were given a 3 -h stabilization period, before baseline samples were being collected (four samples). Subsequently, the rats were placed in the shock-probe burying apparatus for $45 \mathrm{~min}$ (three sample periods). One group was exposed to an electrified probe, whereas the probe was not electrified for a second, control group. Following exposure to the shock-probe, animals were returned to the microdialysis bowl for an additional six sample periods. Throughout the session, dialysate samples were collected every $15 \mathrm{~min}$ and analyzed immediately online for ACh content with HPLC coupled to electrochemical detection.

Experiment $1 \mathrm{~B}$ : retention. At 7 days after Experiment $1 \mathrm{~A}$, animals were returned to the shock-probe apparatus. Animals from either group in Experiment 1A were exposed to either an electrified or a nonelectrified probe. In addition, there were some animals that received a shock during the training phase that did not make contact with the probe during the retention phase. Therefore, there were five different groups for Experiment 1B: (1) rats that did not receive a shock during either session (shock off-shock off; control; $n=5$ ); (2) rats that did not receive a shock in Experiment 1A, but were exposed to an electrified probe in Experiment 1B (shock off-shock on; $n=5$ ); (3) rats that received a shock in both sessions (shock on-shock on; $n=6)$; (4) rats that received a shock in Experiment $1 \mathrm{~A}$, but not in Experiment 1B (shock on-shock off; $n=5$ ); and (5) rats that received a shock in Experiment 1A, but failed to make contact with the probe in Experiment $1 \mathrm{~B}$ (shock on-no contact; $n=3$ ). 


\section{In Vivo Microdialysis ACh Measurements}

ACh determination in hippocampal dialysates was performed as described (Damsma et al, 1988) with some modifications (Tzavara et al, 2003).

Experiment 2. Rats were injected with vehicle (distilled water) or Fluoxetine hydrochloride (Eli Lilly and Company, Indianapolis, IN; $15 \mathrm{mg} / \mathrm{kg}$ ) $1 \mathrm{~h}$ prior to being placed in the shock-probe burying test. They were subsequently exposed to a $15 \mathrm{~min}$ shock-probe session and tested for retention 1 week later. The dose of fluoxetine was based on pilot work in our laboratory and previously obtained neurochemical data (Bymaster et al, 2002).

Experiment 3. Rats were implanted with microdialysis guide cannulae as described above. On the testing day, animals were given a 3-h stabilization period, before baseline samples were being collected (four samples). Subsequently, vehicle (distilled water) or fluoxetine $(15 \mathrm{mg} / \mathrm{kg})$ was injected systemically and hippocampal ACh efflux was measured for an additional 12 samples.

Experiment 4. In Experiment 4, rats were exposed to the shock-probe apparatus during both a training and a retention session. The protocol followed during the training and retention sessions were similar to those described for Experiment 1 with the exception that rats were injected with vehicle or fluoxetine $1 \mathrm{~h}$ prior to the training session. Furthermore, unlike Experiment 1, the probe was electrified for both groups during the training session and was not electrified during the retention session.

Experiment 5. This Experiment was similar to Experiment 2 , except that rats were injected with vehicle (distilled water) or a muscarinic receptor 1 (M1) antagonist (pirenzepine; 25 or $75 \mathrm{mg} / \mathrm{kg}$ ). The dose and method of administration of pirenzepine were based on previous work, where a dose of $75 \mathrm{mg} / \mathrm{kg}$, but not $25 \mathrm{mg} / \mathrm{kg}$, was shown to have behavioral effects in a passive avoidance task (Worms et al, 1989).

\section{RESULTS}

In Experiment $1 \mathrm{~A}$, we demonstrated that exposure to an aversive stimulus increases hippocampal ACh efflux. Statistical evaluation with a two-way ANOVA revealed that there were significant interaction $\left(\mathrm{F}_{12,276}=7.02, p<0.0001\right)$ and treatment $\left(\mathrm{F}_{12,276}=5.29, p<0.001\right)$ effects. Subsequent analysis with $t$-tests between individual time points revealed that rats exposed to an electrified probe (shock on) during the training session had increased hippocampal ACh levels compared to animals in the control group that were exposed to a nonelectrified probe (shock off, Figure 1a and b). Hippocampal ACh levels were elevated while the rats were confined to the shock-probe chamber and remained elevated for two additional sample periods after the rats were returned to the microdialysis bowl (Figure 1a). As expected, these animals were more anxious since they buried the probe significantly more compared to control animals $\left(t_{1,24}=3.94, p<0.001\right.$; Figure $\left.1 c\right)$, although no difference in their overall locomotor activity was found $(p>0.05$; Figure $1 \mathrm{~d})$.

Next, in Experiment 1B, we showed that the memory of an aversive stimulus also increases hippocampal ACh efflux. As a matter of fact, we found that the memory of the initial event had a greater neurochemical impact than exposure to the event itself (compare Figures $1 \mathrm{a}$ to $2 \mathrm{~b}$ and c). Statistical evaluation of the different groups during the retention session with an overall two-way ANOVA revealed significant interaction $\left(\mathrm{F}_{48,228}=11.30, p<0.001\right)$ and treatment $\left(\mathrm{F}_{4,228}=7.39, p<0.05\right)$ effects. Subsequent analysis with a one-way ANOVA between individual time points revealed significant effects $30 \mathrm{~min}\left(\mathrm{~F}_{4,19}=4.92, p<0.01\right)$ and $45 \mathrm{~min}$ $\left(\mathrm{F}_{4,19}=3.74, p<0.05\right)$ after the animal was exposed to the shock-probe chamber. Hippocampal ACh levels were only significantly increased during the subsequent retention session, if the animals made contact with an electrified probe during the training session regardless of whether the probe was electrified or not during the retention session (Figure 2). Therefore, the increase in hippocampal ACh was dependent on the animal's memory of its experience 7 days earlier, but not on the animal's current condition or performance during retention. Animals that were exposed to an electrified probe during training and either made contact with (1) an electrified probe (shock on-shock on), (2) a nonelectrified probe (shock on-shock off), or (3) failed to make contact with the probe (shock on-no contact) during retention all showed significant increases in hippocampal ACh efflux (Figure $2 \mathrm{~b}-\mathrm{e}$ ). Of note, Figure $2 \mathrm{~b}$ illustrates that in spite of the fact that animals were now presented with a nonelectrified probe, the neurochemical response was based on their previous experience with an electrified probe. Furthermore, rats presented with a nonelectrified probe during training and an electrified probe during retention (shock off-shock on) showed similar ACh levels as rats that were exposed to a nonelectrified probe during both sessions (control; shock off-shock off) (Figure 2a and e). Although neurochemical differences between the two groups were not detected, they did differ behaviorally, in that the shock off-shock on group, but not the control group, displayed burying behavior during the retention session (data not shown). The fact that this group made contact with an electrified probe and buried the probe shows that the increase in hippocampal ACh is not the result of the animal's burying behavior or its contact with an electrified probe. In addition, animals that had an enhanced memory of the probe during the retention session (shock on-no contact) had a tendency to display more burying time than the other animals that were exposed to an electrified probe during the training session (Figure 2f), suggesting that enhanced memory of an aversive situation can result in increased anxiety levels. A correlational analysis examining each animal's behavior and neurochemical changes during training and retention sessions showed that burying behavior during retention was significantly correlated with burying behavior during training $\left(r^{2}=0.59\right.$, $p<0.01$ ), but increases in hippocampal ACh efflux during retention were not correlated with those seen during training $\left(r^{2}=0.04, p>0.05\right)$. This further emphasizes that neurochemical differences were not correlated with behavioral performance. The results were not confounded by differences in locomotor activity between groups in either 


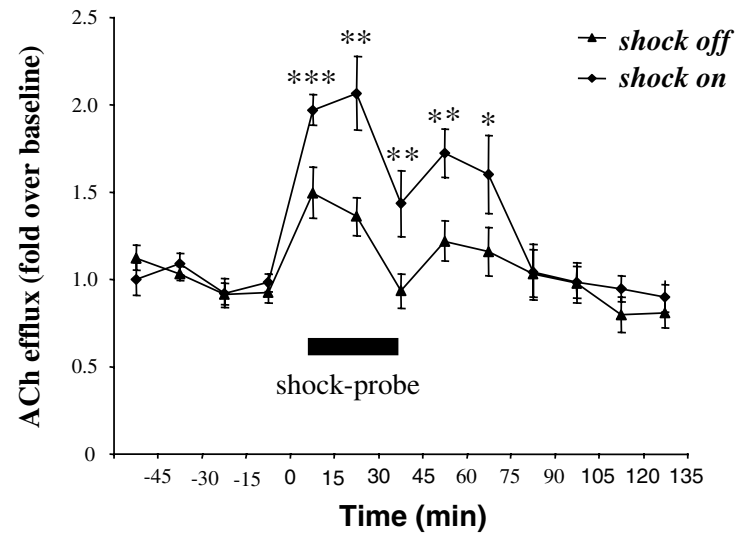

b

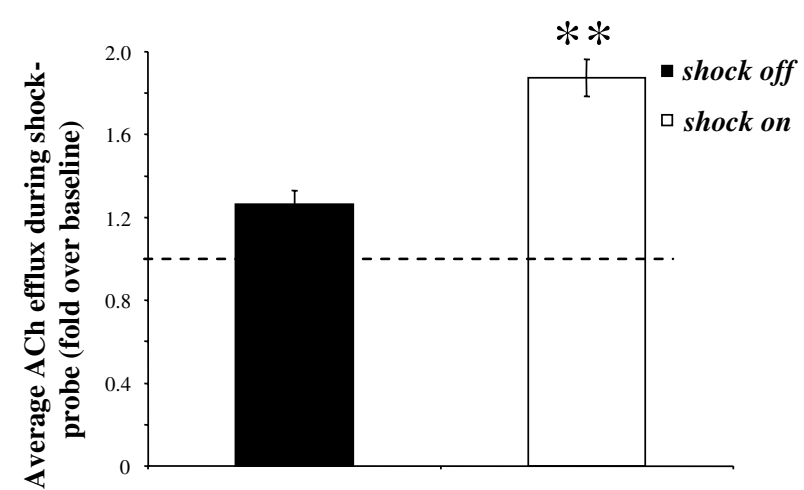

C

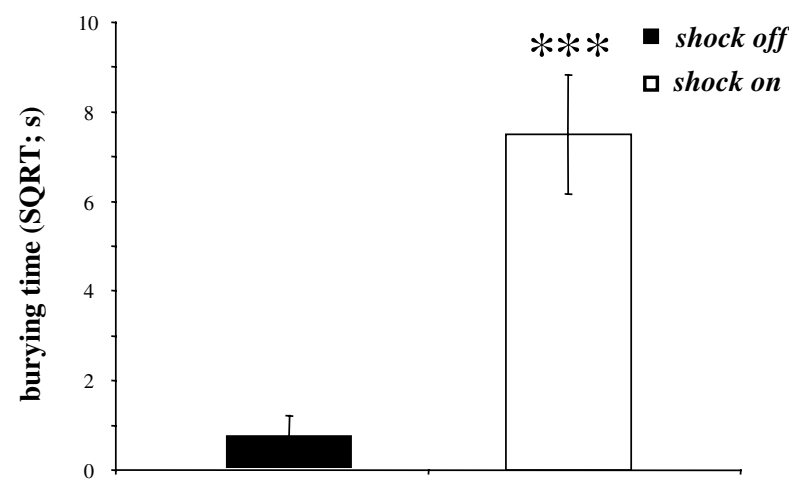

d

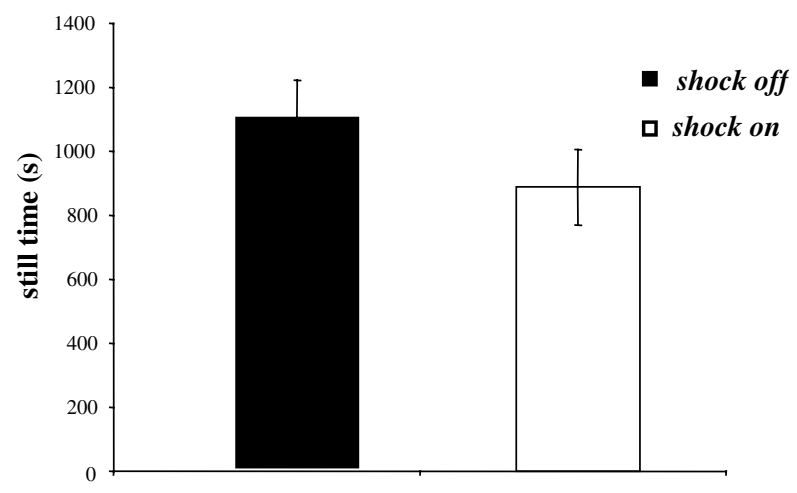

Figure I Exposure to an electrified probe significantly increased hippocampal ACh efflux and burying behavior compared to the presentation of a nonelectrified probe (a, c). (b) The average ACh levels collected while the animal was in the shock-probe burying chamber. Activity levels in the two groups were not different (d). Data (expressed as fold over baseline established prior to any treatment) represent mean \pm SEM of $n=10-14$ animals per group. **** $p<0.00$ I, $* * p<0.0$ I, $* p<0.05$ compared to the control group (shock off). Basal ACh levels were $1035 \pm 28 \mathrm{fmol} \mathrm{ACh} / \mathrm{I} 5 \mathrm{~min}$.

experiment (see data in training session in Figure 1d; data in retention session not shown).

Subsequently, we determined that anxiolytics mediate their actions by counteracting the increase in hippocampal $\mathrm{ACh}$ release evoked by an aversive stimulus and the memory of that stimulus. We used an SSRI rather than benzodiazepines to demonstrate this neurobiological anxiolytic drug action since, unlike benzodiazepines, SSRIs have not been shown to affect basal hippocampal ACh levels. In Experiment 3, fluoxetine was administered acutely, given that chronic administration of SSRIs is not required to show an anxiolytic effect in animals (Brocco et al, 2002; Muraki, 2001). This may be due to the fact that the animals tested do not suffer from unusually low serotonin levels as those purportedly found in the clinical population. Furthermore, acute injections of fluoxetine seem particularly applicable since acute injections of fluoxetine have been shown to be sufficient in raising brain serotonin and, unlike other SSRIs, cortical catecholamine levels as well (Bymaster et al, 2002). As expected, injections of fluoxetine significantly decreased anxiety during a training session $(\mathrm{t}(1,14)=2.27, p<0.05)$, while not affecting cognitive performance in the shockprobe test during training and retention sessions (Experiment 3; Figure $4 \mathrm{a}$ and $\mathrm{c}$ ). There was a tendency for fluoxetine to reduce the retention latency $(p=0.08)$, which likely occurred because fluoxetine reduced the overall salience of the aversive stimulus. In spite of the effects on behavior, fluoxetine injections did not affect basal hippocampal ACh levels (Experiment 3; Figure 3). The behavioral effects occurred in the absence of a significant effect on activity levels, reactivity to the probe, or the number of contacts made with the probe $(p>0.05$ for all measures, although there was a tendency to suppress activity levels, $p=0.14$; Figure $4 \mathrm{a}$ and $\mathrm{b}$ ). While fluoxetine did not affect basal ACh levels, the results from Experiment 4 demonstrate that an injection of fluoxetine $1 \mathrm{~h}$ prior to a training session completely abolished the increase in ACh levels induced by exposure to an electrified probe (Figure $5 \mathrm{a}$ and $\mathrm{b}$ ). In fact, fluoxetine-injected animals showed similar ACh levels compared to animals that did not receive a shock during the training session (see Figure 1a, shock off group). Analysis with a two-way ANOVA revealed a significant interaction effect $(\mathrm{F}(16,144)=7.56, p<0.05)$. Subsequent analysis with $t$-tests between individual time points showed that rats injected with vehicle had significantly higher $\mathrm{ACh}$ levels compared to fluoxetine injected animals up to $60 \mathrm{~min}$ after the rat was placed in the shock-probe test (Figure 5a). As we had hypothesized, animals that were treated with fluoxetine prior to the training session also showed suppressed ACh levels during a subsequent retention session (Figure 5c and d). Again, a two-way ANOVA showed a significant interaction effect $(\mathrm{F}(12,96)=8.69, p<0.05)$. Additional analysis with $t$-tests between individual time points revealed that the fluoxetine induced suppression in 

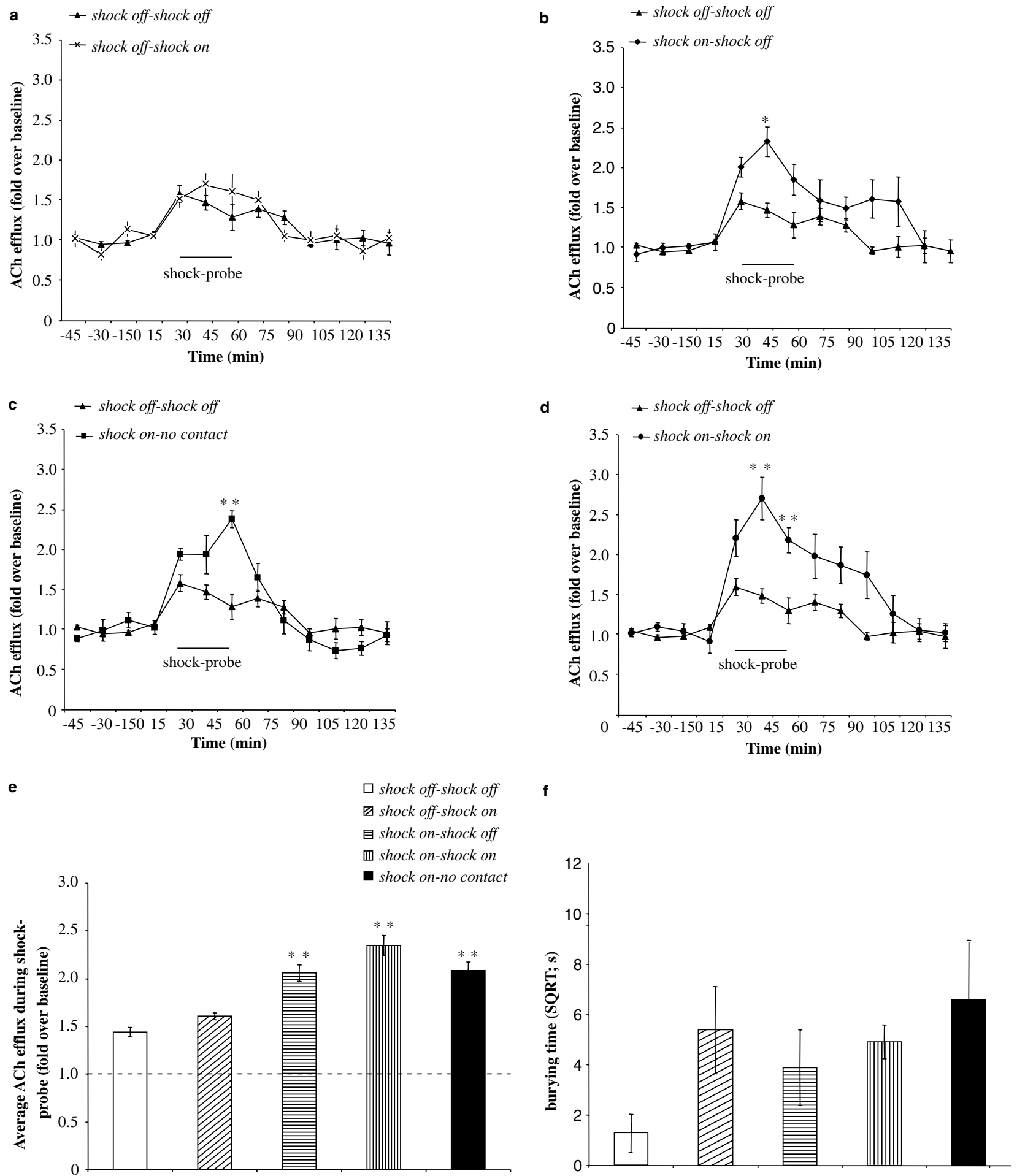

Figure 2 Retention session. Whereas hippocampal ACh efflux was not raised above control (shock off-shock off) levels for shock off-shock on rats (a), the shock on-shock off, shock on-no contact, and the shock on-shock on groups all had significantly raised hippocampal ACh levels while the animal was in the shock-probe burying chamber (b-d). (e) Average ACh efflux collected while the animals were in the shock-probe burying chamber. All animals that received a shock during the training or retention sessions displayed more burying behavior than animals that did not receive a shock in either session ( $\mathrm{f}$. Data (expressed as fold over baseline established prior to any treatment) represent mean \pm SEM of $n=3-6$ animals per group. *** $p<0.0$ I, * $p<0.05$ compared to the control group (shock off-shock off). Basal ACh levels were $762 \pm 25 \mathrm{fmol} \mathrm{ACh} / \mathrm{I} 5 \mathrm{~min}$.

hippocampal ACh efflux reached significance 15 min after the animal was returned to the shock probe apparatus $(\mathrm{t}(1,8)=3.45, p<0.01)$. The fact that anxiolytics suppress the neurochemical impact of an aversive memory, further illustrates the significance of aversive memories in anxiety disorders. The results suggest that although fluoxetinetreated animals can associate the shock with the probe and have an emotional response to the probe (burying 


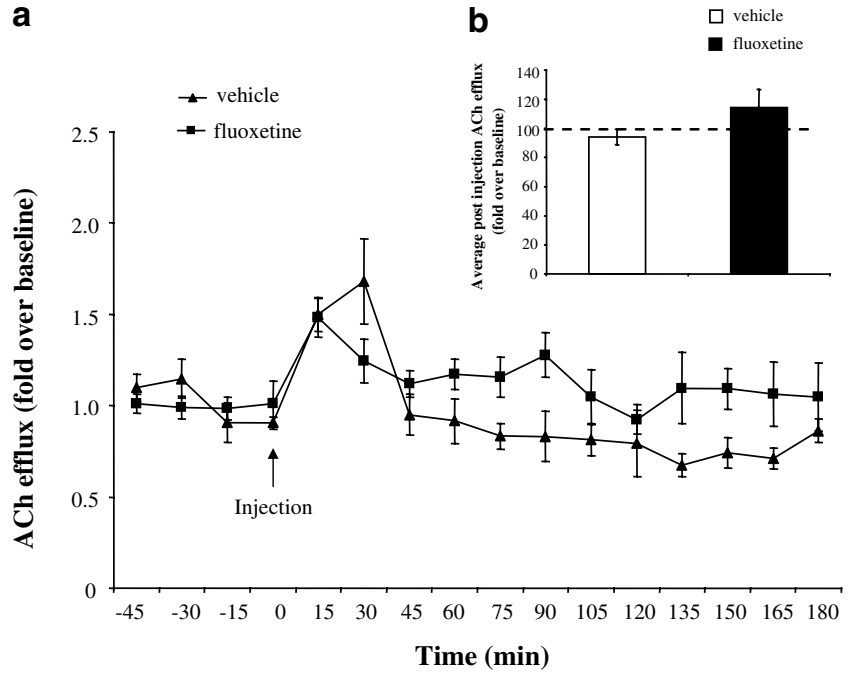

Figure 3 Systemic injections of fluoxetine $(15 \mathrm{mg} / \mathrm{kg})$ did not significantly affect basal ACh levels compared to vehicle injections (a). Averaged postinjection ACh levels also did not significantly differ between groups (b). Data (expressed as fold over baseline established prior to any treatment) represent mean \pm SEM of $n=5$ animals per group. Basal ACh levels were $752 \pm 12 \mathrm{fmol} \mathrm{ACh} / 15 \mathrm{~min}$ behavior), the magnitude of this emotional impact is not as great as for vehicle-injected animals (lower ACh levels and decreased burying behavior). Thus, it appears that fluoxetine may mediate its anxiolytic effect by preventing the evoked hippocampal ACh release caused by anxiety-provoking events. Our final experiment (Experiment 5) demonstrated that the fluoxetine-induced decrease in the enhanced cholinergic neurotransmission is possibly mediated through M1 muscarinic receptors. This possibility arises from the finding that systemic injections of the M1 muscarinic receptor antagonist pirenzepine induced a similar effect on anxiety and cognition as injections of fluoxetine (Figure 6ad). Specifically, injections of pirenzepine significantly decreased burying time during the training session $(\mathrm{F}(2$, 26) $=7.50, p<0.01$; Figure $6 \mathrm{a}$ ) and had no significant effect on cognitive or activity measures during the training and retention sessions ( $p>0.05$, although there was a tendency to suppress activity levels, $p=0.08$; Figure $6 \mathrm{~b}-\mathrm{d}$ ).

\section{Discussion}

The present study indicates that exposure to the shockprobe burying test during both training and retention a

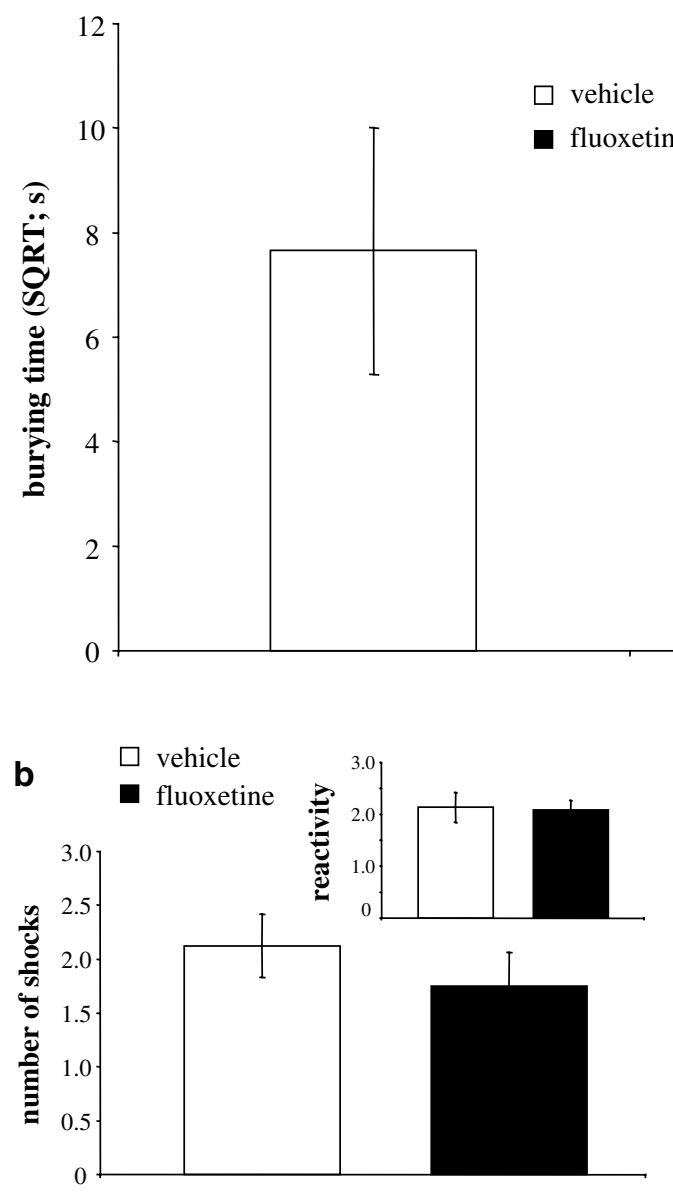

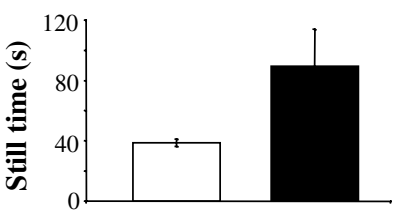

。

$\square$ vehicle

aluoxetine

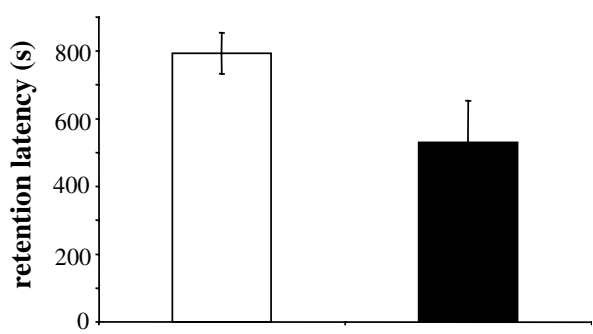

Figure 4 Systemic injections of fluoxetine $(15 \mathrm{mg} / \mathrm{kg}$ ) significantly reduced burying time (a). There was no effect on activity or reactivity to the probe, the number of shocks, or retention latency $(a-c)$. Data represent mean \pm SEM of $n=8$ animals per group. $* p<0.05$ compared to the vehicle injected group. 


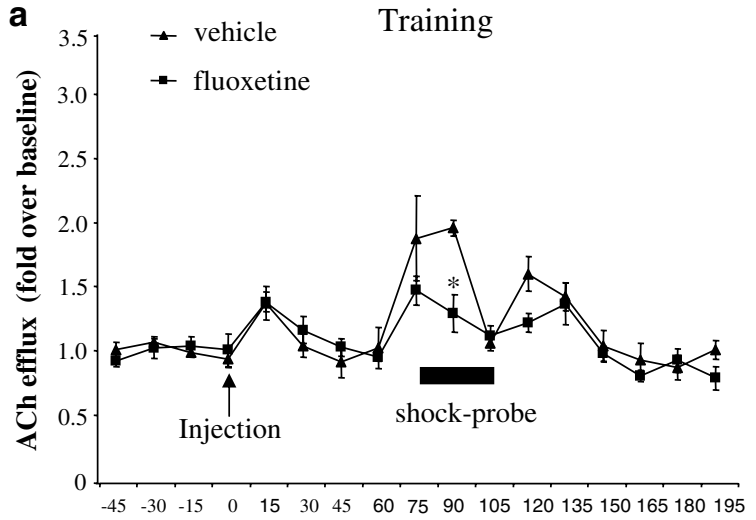

b

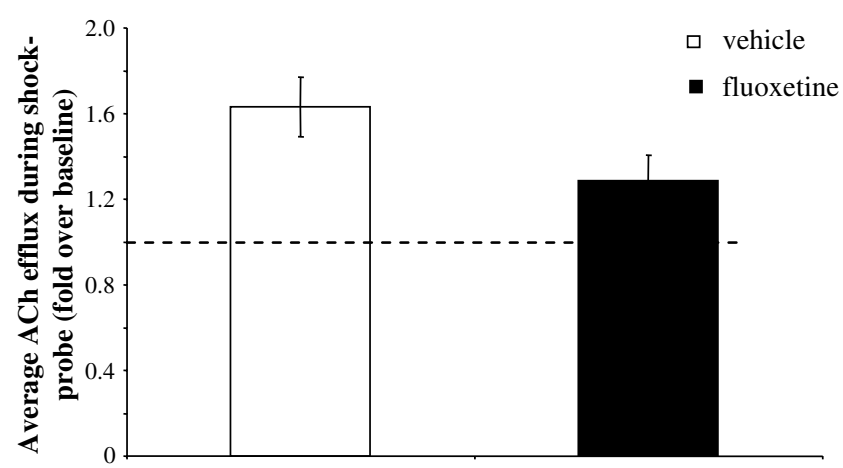

C

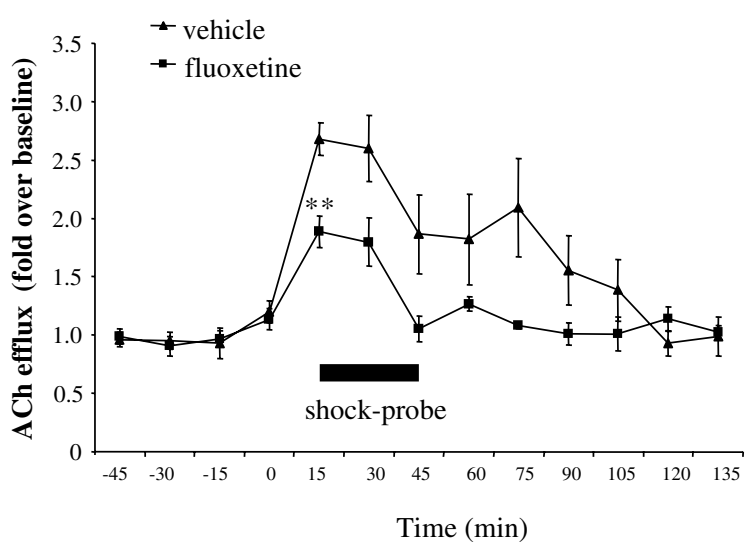

d

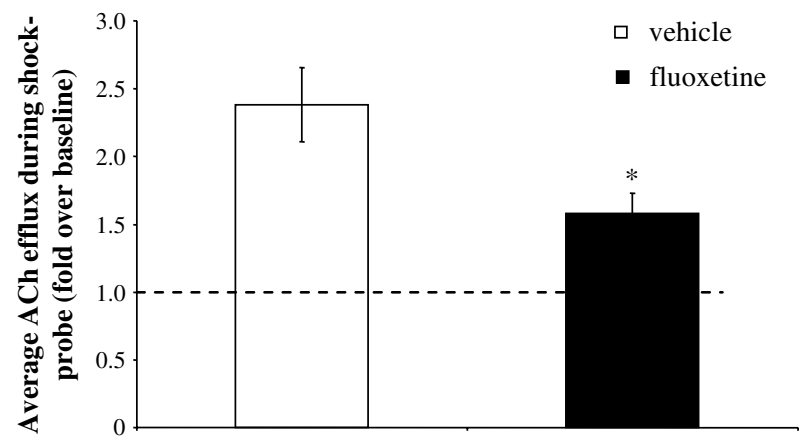

Figure 5 Systemic injections of fluoxetine $(15 \mathrm{mg} / \mathrm{kg})$ significantly reduced the increase in hippocampal ACh levels induced by exposure to an electrified probe during training (a) as well as a subsequent retention session (c). (b and d) Averaged ACh levels collected while the animal was exposed to the shockprobe test during a training and retention session, respectively. Data (expressed as fold over baseline established prior to any treatment) represent mean \pm SEM of $n=5-6$ animals per group. $* p<0.05$, $* * p<0.01$ compared to vehicle injected animals. Basal ACh levels were $1310 \pm 24 \mathrm{fmol} A C h / 15 \mathrm{~min}$ for the training session, and $980 \pm 20 \mathrm{fmol} A C h / 15$ min for the retention session.

sessions, significantly increased hippocampal ACh efflux provided that the probe was electrified during the training session. These results are in part supported by other studies that demonstrate that stressful situations increase $\mathrm{ACh}$ levels in the hippocampus (eg Degroot et al, 2004). In addition, numerous other studies have implicated the hippocampus in memory formation and have attributed an increase in hippocampal ACh efflux to an enhancement of overall memory performance (see eg Fadda et al, 2000; Kopf et al, 2001; Stancampiano et al 1999). The increase in hippocampal ACh efflux observed during the training and retention sessions were abolished by a single systemic injection of fluoxetine $1 \mathrm{~h}$ prior to the training session, even though basal hippocampal ACh levels were not affected. Furthermore, both systemic injections of fluoxetine and pirenzepine $1 \mathrm{~h}$ prior to the training session significantly reduced anxiety levels as demonstrated by a decrease in burying behavior. None of the results were confounded by changes in locomotor activity, reactivity to the probe, or memory of the probe. In view of the findings that increased locomotor activity has also been shown to increase hippocampal ACh levels (Bianchi et al, 2003; Giovannini et al, 2001), the present data suggest that the observed increase in hippocampal $\mathrm{ACh}$ is related to the emotional impact of the event and the memory of that event. In further support of this notion, there was a correlation between the behavioral, but not the neurochemical response during the training and retention sessions. This absence of a correlation between the animal's behavior and hippocampal ACh has also been found in other studies (eg Thiel et al, 1998).

Our data demonstrate that anxiolytics disrupt the integration of anxiety and aversive memories that is mediated through the hippocampal cholinergic system. Anxiety-provoking events as well as aversive memories have a similar neurochemical response, that is, they both elicit an increase in hippocampal ACh release. Treatment with anxiolytics counteracts this physiological response. The fact that the observed neurochemical change persists even in the absence of the initial aversive conditions could explain some of the difficulties associated with the treatment of anxiety disorders. In fact, the memory of an anxiety-provoking event is more important than the event itself and results in greater increases in hippocampal ACh than those induced by the original presentation of that stimulus. Conversely, the rise in hippocampal ACh efflux induced by the presentation of an aversive stimulus does not occur if this stimulus was previously presented as being nonaversive. Specifically, in the shock off-shock on group from Experiment 1B, ACh efflux from the hippocampus did not increase above control values. This suggests that increased ACh levels during the retention session are strictly due to aversive memory formation. 

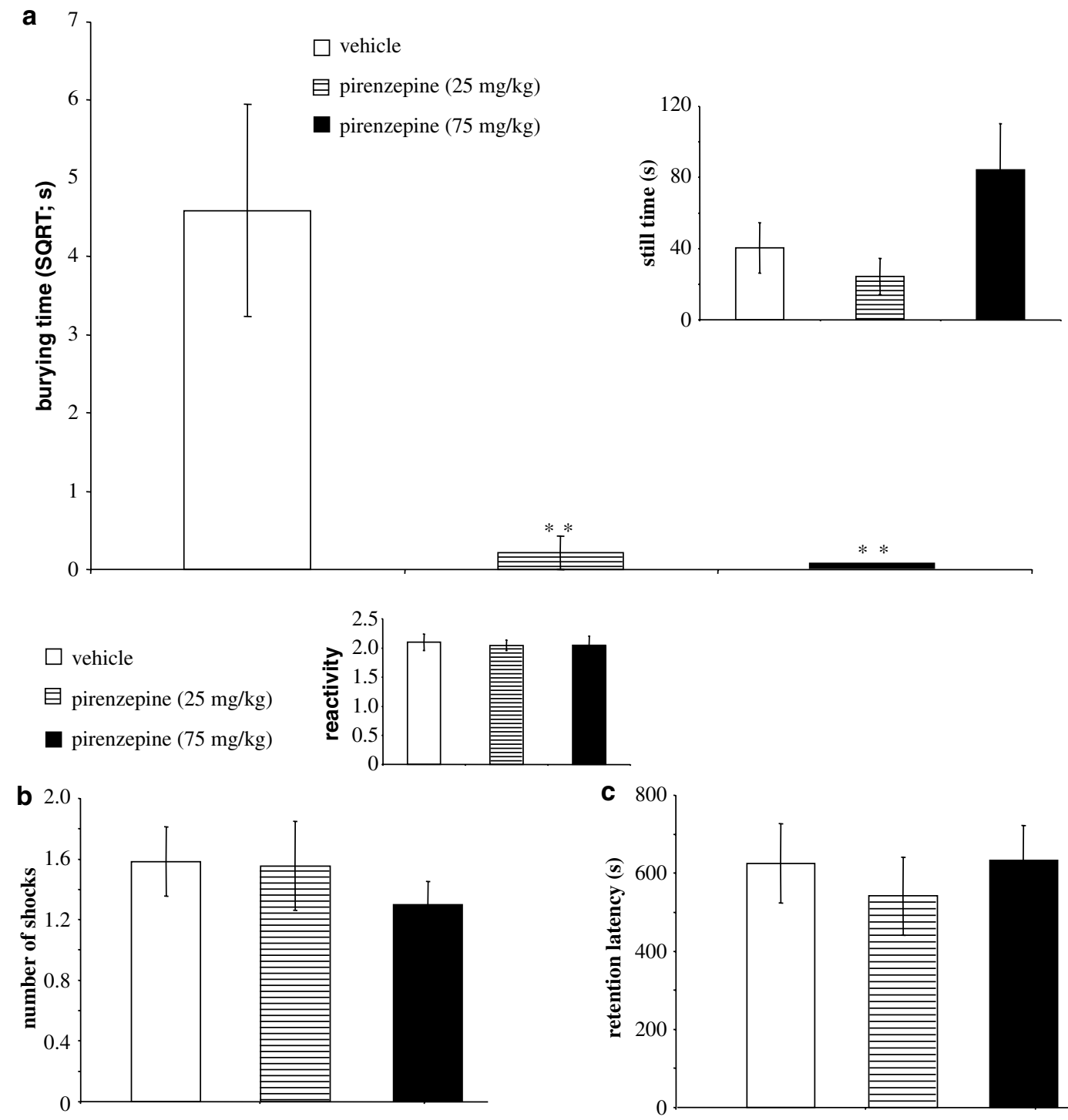

Figure 6 Systemic injections of pirenzepine $(25$ and $75 \mathrm{mg} / \mathrm{kg}$ ) significantly reduced burying time (a). There was no effect on activity or reactivity to the probe, the number of shocks, or retention latency $(a-c)$. Data (expressed as fold over baseline established prior to any treatment) represent mean \pm SEM of $n=8-12$ animals per group. $* * 0<0.01$ compared to vehicle-injected animals.

We show that anxiolytics like fluoxetine prevent the increase in hippocampal ACh levels observed upon initial and subsequent exposure to an aversive stimulus. In addition, we provide parallel evidence that fluoxetine's anxiolytic action may be mediated through a decrease of aversive stimulus- and aversive memory-evoked increases in cholinergic neurotransmission through M1 muscarinic receptors in the hippocampus, although this evidence is strictly circumstantial and needs to be further investigated in future studies. It seems unlikely that injections of pirenzepine induced an anxiolytic effect by reducing overall ACh efflux since previous studies have reported that pirenzepine either increases or does not affect ACh efflux (Douglas et al, 2001; Mishima et al, 2000). Therefore, the observed effect seems to be solely attributed to a blockade of the M1 receptors.
Other studies in part support the results obtained with pirenzepine, by demonstrating that blockade of M1, but not M2, muscarinic receptors in the hippocampus modulates anxiety levels (File et al, 1998; Sienkiewicz-Jarosz et al, 2000). On the other hand, some other work, including data from our own laboratory, has previously shown that increasing cholinergic tone may decrease anxiety (Degroot and Treit, 2003; File et al, 1998). However, these previous studies used a different method of administration or animal models in which SSRIs have yielded inconsistent results. In addition, ACh levels were modulated prior to exposing the animal to an anxiety-provoking situation. This contrasts with the current study where we simply block the neurochemical event that occurs during anxiety. It has been previously proposed that raising ACh levels prior to inducing anxiety may serve as a 'coping mechanism' 
(Smythe et al, 1998), allowing for better awareness while the animal is being tested, which may reduce anxiety. The effect on future anxiety (as in the current study) has never been examined. In addition, it has been suggested that raising hippocampal ACh efflux prior to an anxiety-provoking situation may actually result in a stimulation of septal GABAergic receptors, which may actually reduce ACh efflux in the hippocampus at a later time point (ie while the animal is being tested; Degroot and Treit, 2003).

Our data raise the possibility that all anxiolytics may ultimately exert their clinical effects through a common mechanism, which is a reduction in anxiety-evoked increases in cholinergic neurotransmission possibly through M1 muscarinic receptors in the hippocampus. Other studies have demonstrated that systemic injections of benzodiazepines reduce hippocampal ACh efflux (Dazzi et al, 1995b). On the other hand, anxiogenic compounds like flumazenil increase hippocampal ACh levels (Imperato et al, 1994). Whereas both benzodiazepines and SSRIs prevent anxiety-induced increases in hippocampal ACh levels, only benzodiazepines affect basal ACh levels (Dazzi et al, 1995a, b; Degroot et al, 2004). This could explain why both benzodiazepines and SSRIs diminish aversive memory formation, but only benzodiazepines impair overall cognitive performance. Current treatment of anxiety disorders is often associated with adverse side effects and is not always effective. Our data provide the possibility that anxiety disorders may be ultimately controlled through a precise targeting of the hippocampal cholinergic system. Although it is known how benzodiazepines reduce ACh efflux in the hippocampus, the serotonergic receptor(s) and the precise neuroanatomical site(s) that mediate actions of SSRIs on the hippocampal cholinergic mechanisms integrating anxiety and aversive memory remain to be elucidated.

\section{ACKNOWLEDGEMENTS}

All research was funded by Eli Lilly and Company.

\section{REFERENCES}

Atack JR (2003). Anxioselective compounds acting at the GABA(A) receptor benzodiazepine binding site. Curr Drug Target CNS Neurol Disord 2: 213-232.

Bell MA, Wolfe CD (2004). Emotion and cognition: an intricately bound developmental process. Child Dev 75: 366-370.

Bianchi L, Ballini C, Colivicchi MA, Della Corte L, Giovannini MG, Pepeu G (2003). Investigation on acetylcholine, aspartate, glutamate and GABA extracellular levels from ventral hippocampus during repeated exploratory activity in the rat. Neurochem Res 28: 565-573.

Bourin M, Hascoet M (2001). Drug mechanisms in anxiety. Curr Opin Invest Drugs 2: 259-265.

Brocco M, Dekeyne A, Veiga S, Girardon S, Millan MJ (2002). Induction of hyperlocomotion in mice exposed to a novel environment by inhibition of serotonin reuptake. A pharmacological characterization of diverse classes of antidepressant agents. Pharmacol Biochem Behav 71: 667-680.

Bymaster FP, Zhang W, Carter PA, Shaw J, Chernet E, Phebus L et al (2002). Fluoxetine, but not other selective serotonin uptake inhibitors, increases norepinephrine and dopamine extracellular levels in prefrontal cortex. Psychopharmacology 160: 353-361.
Clark DM, McManus F (2002). Information processing in social phobia. Biol Psychiatry 51: 92-100.

Cole SO (1986). Effects of benzodiazepines on acquisition and performance: a critical assessment. Neurosci Biobehav Rev 10: 265-272.

Crestani F, Lorez M, Baer K, Essrich C, Benke D, Laurent JP et al (1999). Decreased GABAA-receptor clustering results in enhanced anxiety and a bias for threat cues. Nat Neurosci 2: 833-839.

Damsma G, Westerink BH, de Boer P, de Vries JB, Horn AS (1988). Basal acetylcholine release in freely moving rats detected by online trans-striatal dialysis: pharmacological aspects. Life Sci 43: $1161-1168$.

Dazzi L, Motzo C, Imperato A, Serra M, Gessa GL, Biggio G (1995a). Modulation of basal and stress-induced release of acetylcholine and dopamine in rat brain by abecarnil and imidazenil, two anxioselective gamma-aminobutyric acidA receptor modulators. J Pharmacol Exp Ther 273: 241-247.

Dazzi L, Motzo C, Maira G, Sanna A, Serra M, Biggio G (1995b). Enhancement of acetylcholine release by flumazenil in the hippocampus of rats chronically treated with diazepam but not with imidazenil or abecarnil. Psychopharmacology 121: 180-185.

De Boer SF, Slangen JL, Van der Gugten J (1990). Plasma catecholamine and corticosterone levels during active and passive shock probe avoidance in rats: effects of chlordiazepoxide. Pharmacol Biochem Behav 47: 1089-1098.

Decker MW, Curzon P, Brioni JD, Americ SP (1994). Effects of ABT-418, a novel cholinergic channel ligand, on place learning in septal-lesioned rats. Eur J Pharmacol 261: 217-222.

Degroot A, Kashluba S, Treit D (2001). Septal GABAergic and hippocampal cholinergic systems modulate anxiety in the plus-maze and shock-probe tests. Pharmacol Biochem Behav 69: 391-399.

Degroot A, Treit D (2002). Dorsal and ventral hippocampal cholinergic systems modulate anxiety in the plus-maze and shock-probe tests. Brain Res 949: 60-70.

Degroot A, Treit D (2003). Septal GABAergic and hippocampal cholinergic systems interact in the modulation of anxiety. Neuroscience 117: 493-501.

Degroot A, Treit D (2004). Anxiety is functionally segregated within the septo-hippocampal system. Brain Res 1001: 60-71.

Degroot A, Wade M, Davis R, Salhoff C, Nomikos GG (2004). Chlordiazepoxide, but not buspirone blocks the increase in hippocampal cholinergic levels induced by exposure to an elevated platform. Eur J Pharmacol 493: 103-109.

Douglas CL, Baghdoyan HA, Lydic R (2001). M2 muscarinic autoreceptors modulate acetylcholine release in the prefrontal cortex of C57BL/6J mouse. J Pharmacol Exp Ther 299: 960-966.

Egawa T, Mishima K, Egashira N, Fukuzawa M, Abe K, Yae T et al (2002). Impairment of spatial memory in kaolin-induced hydrocephalic rats is associated with changes in the hippocampal cholinergic and noradrenergic contents. Behav Brain Res 129: $31-39$.

Fadda F, Cocco S, Stancampiano R (2000). Hippocampal acetylcholine release correlates with spatial learning performance in freely moving rats. Neuroreport 11: 2265-2269.

Fanselow MS (2000). Contextual fear, gestalt memories, and the hippocampus. Behav Brain Res 110: 73-81.

File SE, Gonzalez LE, Andrews N (1998). Endogenous acetylcholine in the dorsal hippocampus reduces anxiety through actions on nicotinic and muscarinicl receptors. Behav Neourosci 112: 352-359.

Frye CA, Seliga AM (2003). Olanzapine's effects to reduce fear and anxiety and enhance social interactions coincide with increased progestin concentrations of ovariectomized rats. Psychoneuroendocrinology 28: 657-673.

Giovannini MG, Rakovska A, Benton RS, Pazzagli M, Bianchi L, Pepeu G (2001). Effects of novelty and habituation 
on acetylcholine, GABA, and glutamate release from the frontal cortex and hippocampus of freely moving rats. Neuroscience 106: 43-53.

Hashimoto S, Inoue T, Koyama T (1996). Serotonin reuptake inhibitors reduce conditioned fear stress-induced freezing behavior in rats. Psychopharmacology 123: 182-186.

Imperato A, Dazzi L, Obinu MC, Gessa GL, Biggio G (1994). The benzodiazepine receptor antagonist flumazenil increases acetylcholine release in rat hippocampus. Brain Res 647: 167-171.

Ishigooka J (2003). Benzodiazepine-induced amnesia. Ryoikibetsu Shokogun Shirizu 38: 617-620.

Kawasaki K, Eigyo M, Ikeda M, Kihara T, Koike K, Matsushita A et al (1996). A novel benzodiazepine inverse agonist, S-8510, as a cognitive enhancer. Prog Neuropsychopharmacol Biol Psychiatry 20: 1413-1425.

Kopf SR, Buchholzer ML, Hilgert M, Loffelholz K, Klein J (2001). Glucose plus choline improve passive avoidance behaviour and increase hippocampal acetylcholine release in mice. Neuroscience 103: 365-371.

Lehmann H, Treit D, Parent MB (2000). Amygdala lesions do not impair shock-probe avoidance retention performance. Behav Neurosci 114: 107-116.

Mishima K, Iwasaki K, Tsukikawa H, Matsumoto Y, Egashira N (2000). The scopolamine-induced impairment of spatial cognition parallel acetylcholine release in the ventral hippocampus in rats. Jpn J Pharmacol 84: 163-173.

Monleon S, Urquiza A, Carmen Arenas M, Vinader-Caerols C, Parra A (2002). Chronic administration of fluoxetine impairs inhibitory avoidance in male but not female mice. Behav Brain Res 136: 483-488.

Muraki I (2001). Behavioral and neurochemical study on the mechanism of the anxiolytic effect of a selective serotonin reuptake inhibitor, a selective serotonin $1 \mathrm{~A}$ agonist and lithium carbonate. Hokkaido Igaku Zasshi 76: 57-70.

Olariu A, Tran MH, Yamada K, Mizuno M, Hefco V, Nabeshima T (2001). Memory deficits and increased emotionality induced by beta-amyloid (25-35) are correlated with the reduced acetylcholine release and altered phorbol dibutyrate binding in the hippocampus. J Neural Transm 108: 1065-1079.

Pain L, Launoy A, Fouquet N, Oberling P (2002). Mechanisms of action of midazolam on expression of contextual fear in rats. Br J Anaesth 89: 614-621.

Pare WP (1996). Enhanced retrieval of unpleasant memories influenced by shock controllability, shock sequence, and rat strain. Biol Psychiatry 39: 808-813.

Pesold C, Treit D (1992). Excitotoxic lesions of the septum produce anxiolytic effects in the elevated plus-maze and shock-probe burying tests. Physiol Behav 52: 37-47.
Pinel JPJ, Treit D (1978). Burying as a defensive response in rats. Comp Physiol Psychol 92: 708-712.

Sanchez C, Meier E (1997). Behavioral profiles of SSRIs in animal models of depression, anxiety and aggression. Are they all alike? Psychopharmacology 129: 197-205.

Shah AA, Treit D (2003). Excitotoxic lesions of the medial prefrontal cortex attenuate fear responses in the elevated-plus maze, social interaction and shock probe burying tests. Brain Res 969: 183-194.

Sienkiewicz-Jarosz H, Czlonkowska AI, Siemiatkowski M, Maciejak P, Szyndler J, Plaznik A (2000). The effects of physostigmine and cholinergic receptor ligands on novelty-induced neophobia. J Neural Transm 107: 1403-1412.

Skelton MR, Ponniah S, Wang DZ, Doetschman T, Vorhees CV, Pallen CJ (2003). Protein tyrosine phosphatase alpha (PTP alpha) knockout mice show deficits in Morris water maze learning, decreased locomotor activity, and decreases in anxiety. Brain Res 984: 1-10.

Smythe JW, Bhatnagar S, Murphy D, Timothy C, Costall B (1998). The effects of intrahippocampal scopolamine infusions on anxiety in rats as measured by the black-white box test. Brain Res Bull 45: 89-93.

Stancampiano R, Cocco S, Cugusi C, Sarais L, Fadda F (1999). Serotonin and acetylcholine release response in the rat hippocampus during a spatial memory task. Neuroscience 89: $1135-1143$.

Thiel CM, Huston JP, Schwarting RK (1998). Hippocampal acetylcholine and habituation learning. Neuroscience 85: $1253-1262$.

Treit D, Menard J (1997). Dissociations among the anxiolytic effects of septal, hippocampal, and amygdaloid lesions. Behav Neurosci 111: 653-658.

Treit D, Menard J, Pesold C (1994). The shock probe burying test. Neurosci Protoc Module 3: 9-17.

Treit D, Pesold C, Rotzinger S (1993). Noninteractive effects of diazepam and amygdaloid lesions in two animal models of anxiety. Behav Neurosci 107: 1099-1105.

Treit D, Pinel JPJ, Fibiger HC (1981). Conditioned defensive burying: a new paradigm for the study of anxiolytic agents. Pharmacol Biochem Behav 15: 619-626.

Tsuda A, Yoshishige I, Tanaka M (1988). The contrasting effects of diazepam and yohimbine on conditioned defensive burying in rats. Psychobiology 16: 213-217.

Tzavara ET, Wade M, Nomikos GG (2003). Biphasic effects of cannabinoids on acetylcholine release in the hippocampus: site and mechanism of action. J Neurosci 23: 9374-9384.

Worms P, Guedet C, Perio A, Soubrie P (1989). Systemic injection of pirenzepine induces a deficit in passive avoidance learning in rats. Psychopharmacology 98: 286-288. 